\title{
Patrimonio europeo: ¿cultura global?
}

La proliferación de iniciativas encaminadas a apuntalar la idea de una identidad cultural europea, como el diseño del Sello Patrimonio Europeo o la proyección de un Museo Europeo de la Memoria, plantea un profundo debate sobre la medida en que existe un patrimonio europeo y de cuál es su papel en el mundo globalizado. Pedro A. Vives opina que la cultura europea como referente universal sólo tendrá cabida en la sociedad actual desde un principio de solidaridad que supere la concepción exótica de lo no europeo.

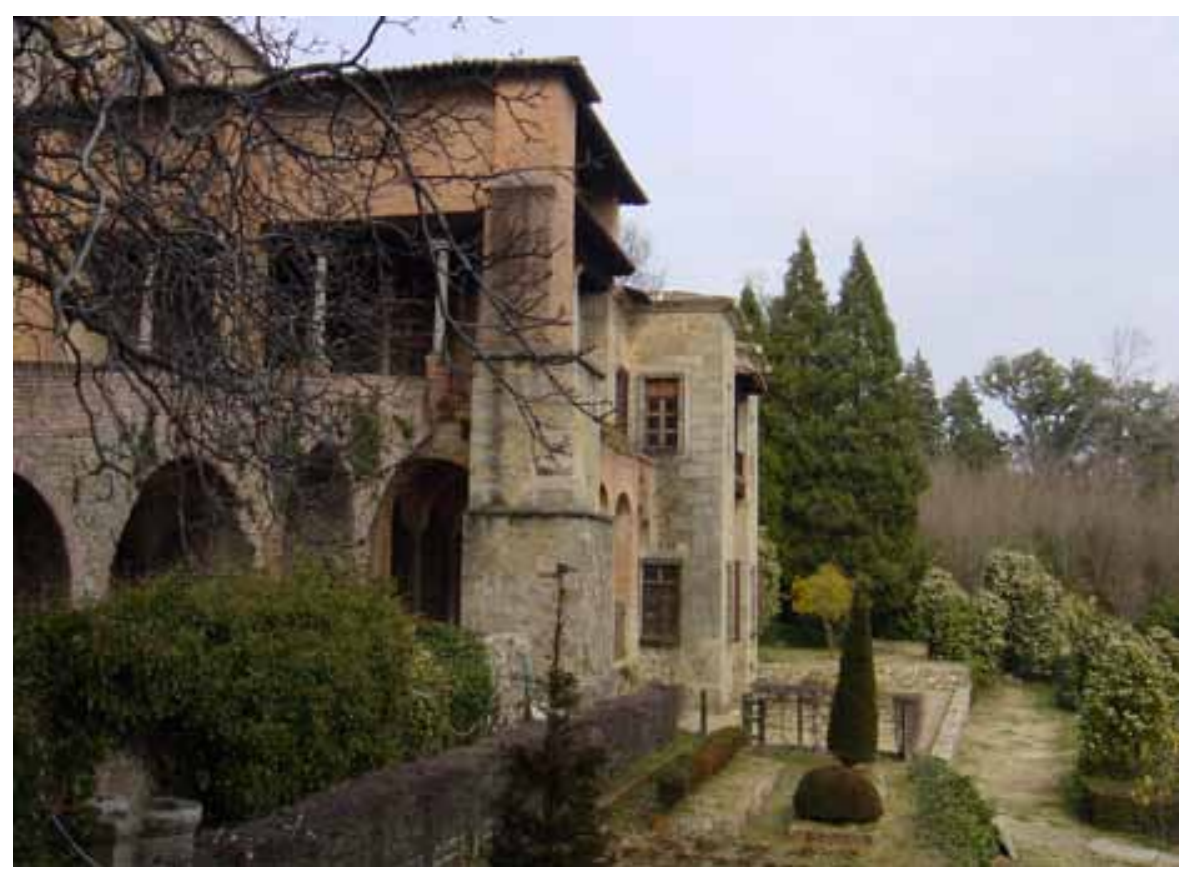

El Monasterio de Yuste (Cuacos de Yuste, Cáceres) cuenta con la declaración del Sello de Patrimonio Europeo. Foto: Sindy Nero

Los acervos, incluso con diversidad, han perdido vigencia en los sistemas culturales contemporáneos. Seguramente eso está pesando en más de una perspectiva de futuro, dificultando la percepción de alguna forma de cambio: cambio ahora se traduce frecuentemente por progreso material sin relacionarlo con transformación de estructuras. Desde luego las ideas de tradición, antigüedad, costumbre, de patrimonio mismo, no protagonizan desde hace algún tiempo la educación contemporánea, bien porque huimos del conservatismo, bien por necesidad de desligar educación de un pasado socialmente desprestigiado. También, a todas luces, por distanciar la realidad actual de manipulaciones identitarias que, a Europa al menos, le reportaron dolorosas interrupciones de su modernización.
Con el siglo XXI apenas estrenado, el patrimonio cultural europeo puede diluirse a veces en obviedad retórica o convención académica. Tal consideración es posible porque la vigencia y pluralidad de sus concreciones llega a envolverlo como parte de una complejidad que aceptamos como cultura global. Una parte sustancial desde luego, incluso nuclear en muchos sentidos, aunque hayamos incorporado un conveniente pudor a declararlo abiertamente. Pero lo cierto es que los resultados materiales de la historia europea proporcionan, además de testimonio, claves y advertencias útiles en el mundo contemporáneo que no solemos tomar en consideración.

Una de las principales, si no la primera, de las reflexiones a que invita el patrimonio de
Europa es que ha sobrevivido a ella misma. Si existe una cultura europea -que por qué no-, sus resultados históricos tienen tanta carga identitaria como admonitoria; proporcionan a estas alturas una Ilamada de atención sobre el valor de la convivencia o la razón de la construcción política que debiéramos ser capaces de transmitir a los herederos de la globalización, con vistas a hacer ésta más humana, más inteligente, más equitativa. Sucede sin embargo que el patrimonio en Europa simboliza mejor la cultura devenida que la cultura activa; nunca ha llegado a incorporarse o ser incorporado a la comunicación -salvo en la feria de los logotipos-y, de últimas, parece emplazado en un extenso territorio delimitado por la raigambre en un extremo y la dinámica del parque temático en el otro.

Es posible afirmar que la identificación, salvaguarda y conservación de su patrimonio han construido para la Europa unida un distintivo de calidad. Calidad en el desarrollo, en la configuración de un campo profesional, en la forja de un concepto conciliador del urbanismo y la conservación, en la puesta a disposición de bienes culturales o, con ejemplaridad, en la definición práctica de la cooperación cultural en todas sus dimensiones. Lo que no cabe afirmar es que el patrimonio haya abordado su trascendencia de lo local a lo general; que sirva de referente a todos los ciudadanos, por ejemplo, de la Unión Europea; que se haya desprendido de notoriedad gloriosa para certificar su valor en el bienestar logrado, en la diversificación laboral, en los incentivos económicos. Estas dimensiones actuales del patrimonio europeo no son meros recursos en foros sobre el tema, son reales y palpables y seguramente lo más tangible de cuanto alude - tan vaga y brevemente- el artículo 167 del Tratado de Lisboa.

No es posible predecir, por ejemplo, si la reciente iniciativa comunitaria de fomentar un "Sello de Patrimonio Europeo" va a encarar el valor de éste en los procesos 
sociales en marcha, si ha de servir a una concertación de las políticas del ramo en todos sus niveles, a la recuperación de la tradición como factor activo de cultura o a un maridaje estratégico, y triangular, entre patrimonio, audiovisual y comunicación. Da la sensación de que no. Hasta ahora a los europeos no nos ha preocupado, entre otras cosas, cultivar un criterio de ligazón entre pasado y futuro que proporcione vigencia a los acervos, que sea capaz de inducir responsabilidad hacia lo heredado y ponderación ante lo novedoso cuando no efímero. De ahi que subsista riesgo de quiebra social alimentada en una diversidad de muestrario, engolosinada con una cultura tecnológica y personalizada, como en otras regiones del mundo. En ese sentido somos globales. La propuesta entonces de otra "red» de intencionalidades, discursos retroalimentados y socios ad hoc no parece base sólida para que averigüemos cómo se nos ha multiplicado el patrimonio precisamente, si la tecnología es ya un bien patrimonial o, sin ir más lejos, en qué va a consistir el patrimonio digital que asoma por la esquina.

Hemos iniciado además un proceso complejo e inacabado de valoración de nuestro patrimonio respecto a la economía global, y eso lo pone en referencia con tendencias demográficas, con nichos de negocio y circulación de bienes, con la acumulación de recursos en un contexto de bienestar. El patrimonio, en la Unión Europea, ha trascendido su esencial carácter simbólico para ofrecerse como fuente de oportunidades, pero no es seguro que esa conversión haya sido comunicada, que esté incorporada a una conciencia europea de ciudadanía ni que la hayamos puesto en juego en las relaciones culturales con otros acervos mundiales.

Y de ahí otra cuestión. Nuestro patrimonio cultural proporciona identidad local, nacional, europea; o eso creemos. Ahora bien, ¿nos hemos liberado los europeos del enfoque exótico de lo no-europeo y no-occidental que ha formado parte de nuestro acervo?
La concepción euro-céntrica del mundo, con todas sus lacras, nos proporcionó muchos de los resultados culturales que más nos halagan, nos abrió los ojos y la mente a lo distinto, a cuestionamientos filosóficos que nos han traído hasta esta contemporaneidad. Y de algo así no es fácil desprenderse; posiblemente lo ha sido en las formas; dudosamente en el fondo. El patrimonio europeo, referente de una cultura que se sabe prolifica y en muchas modalidades paradigmática, necesita todavía rematar la transformación del exotismo heredado hacia sus distintos en una perspectiva solidaria que actualice ante la ciudadanía una idea de lo global. Esa meta, de momento, satisfaría nuestro modo de asumirnos como avanzados y posmodernos.

Pero esa meta encierra una exigencia de comunicación y divulgación más ardua de lo que cabe imaginar y otra de cooperación efectiva; la segunda hace tiempo que crece, pero la primera está aquejada de un serio enanismo. Empieza a ser urgente

\section{ALGUNAS INICIATIVAS PROYECTADAS EN TORNO A LA IDENTIDAD CULTURAL EUROPEA}

- Creación del Sello Patrimonio Europeo Informe de la Unión Europea:

http://eur-lex.europa.eu/LexUriServ/LexUriServ. do?uri=COM:2010:0076:FIN:ES:PDF

- Un Museo Europeo de la Memoria para 2014 Durante la celebración de este seminario se anunció la creación del museo, que tendrá como sede Bruselas:

http://www.mcu.es/novedades/2010/novedades_ memoria_historica.html

- La Biblioteca Digital Europea "Europeana"

La base de datos está disponible en el portal: http://www.europeana.eu

- Libro verde de Industrias culturales y creativas

Ya se puede hacer la consulta online: http://ec.europa.eu/culture/our-policydevelopment/doc2577_en.htm

- La cultura en el centro de la Estrategia Económica "UE 2020"

Noticia ampliada en el siguiente enlace: www.eu2010.es/es/documentosynoticias/noticias/ mar31_rimcultura.html transmitir convicción cívica acerca del valor del patrimonio - de todo patrimonioen la convivencia, el desarrollo social y la generación de riqueza. Y en esa solidaridad desde lo europeo no puede obviar el haber transferido a otras culturas nuestro concepto patrimonial y haberlas, de ese modo, contaminado. La realidad actual lo exige porque la posición relativa de la Unión Europea en el mundo ha experimentado un cambio relevante: en términos económicos y financieros la Unión presenta un efectivo retraso de actualización respecto de Estados Unidos, China o India. Y así como entre los años veinte y sesenta del pasado siglo la iconografía de lo europeo -su patrimonio básicamente - se asoció a una «vieja Europa» por dos veces incapaz de evitarle al mundo el enfrentamiento, pudiera suceder que nuestro flamante patrimonio acabara sirviendo de foto fija de impotencia ante una mundialización tramposa.

Pudiera ser, por añadidura, que la globalización contenga un requisito de des-europeización, algo difícil de concebir para el patrimonio incluso en los folletos turísticos. Una cosa es concebir el patrimonio como emblema solidario, de vocación universalista, y otra distinta desarraigarlo, suspender su territorialidad y su condición histórica concretas. Al fin y al cabo la "cultura global» en nuestros días sólo cabe concebirla como la circulación de conocimiento aneja a esa mundialización económica. Y la tal mundialización, hasta ahora, funciona mejor universalizando fracasos y subastando imaginarios de éxito que viceversa, lo que explica una frustrante espiral de desigualdad. El patrimonio de Europa tomado como referente de cultura global apunta a que la circulación de conocimiento puede ser muy cierta, pero que la capacidad para crearlo, para conservarlo, para ponerlo en valor y a disposición sigue pendiente de un mundo desigual.

\section{Pedro A. Vives}

Consultor cultural 